\author{
AN DRÉS RESÉNDIZ RODEA* \\ INSTITUTO NACIONAL DE BELLAS ARTES, CENIDIAP
}

\title{
Lo húmedo y lo seco Fronteras y polarización social en la plástica mexicana del siglo xIx
}

\begin{abstract}
$\mathrm{E}$ N EL VALLE DE MÉXICo, en la mayor parte del siglo xix, subsistía un eje vertical de depósitos lacustres; de norte a sur se sucedían los lagos de Zumpango, Xaltocan, San C ristóbal, Texcoco, Xochimilco y Chalco. D e manera escalonada las aguas de todos ellos fluían hacia el centro, donde se localizaba el lago de Texcoco, muy cerca del costado oriental de la ciudad de M éxico y a un nivel igual o ligeramente inferior. Chalco y Xochimilco se comunicaban directamente con las orillas de la ciudad por un canal (al que se denominó de distintas maneras: de la Viga, de Xochimilco, de Santa Anita, y otros), para después desembocar sus aguas en el lago de Texcoco por el canal de San Lázaro. Por ello, cuando las lluvias se incrementaban inesperadamente, el peligro de inundaciones apuraba a la ciudad.

Varios aluviones afectaron a nuestra población, pero el más grave de su historia ocurrió entre 1629 y I635, cuando por tiempo prolongado mantuvo a la ciudad bajo cierto nivel de aguas: "El balance era catastrófico: millares de muertos, dos terceras partes de la ciudad arrasadas, los edificios más macizos socavados por las filtraciones. D urante casi cinco años, el comercio había estado paralizado, al igual que casi toda la actividad económica." ${ }^{\text {I }}$

* Agradezco a Ana Garduño su apoyo en rescatar este tema del olvido y por sus comentarios; a Patricia Chavero y Blanca Lamadrid por sus observaciones; a Aurelio Salas por la reproducción de imágenes.

I. Alain M usset, El agua en el valle de M éxico, M éxico, Pórtico de la ciudad de M éxico, Centro de Estudios M exicanos y Centroamericanos, 1992, p. I89.
\end{abstract}


Se menciona que 30 mil indígenas sucumbieron en ese periodo y la mayor parte de las familias de españoles emigraron a poblaciones cercanas, como San Agustín de las Cuevas, Tacuba, Coyoacán, Texcoco e incluso a Puebla. Fue necesario reconstruir y arreglar casas, edificios y puentes. A partir de entonces se intensificaron las reflexiones sobre la conveniencia de desecar las lagunas parcial o totalmente.

En cuanto al siglo xIx, varias inundaciones continuaron afectando con diferente intensidad a la población de la capital, por ejemplo, el desbordamiento de i875 provocó epidemias con una crecida cifra de defunciones en los barrios bajos del norte y del oriente. ${ }^{2}$

A inicios del siglo decimonónico los trabajos del desagüe realizados por los gobiernos virreinales habían sido interrumpidos por problemas políticos y económicos y, en los primeros años de la época independiente, no sólo dejaron de hacerse avances en ese proyecto sino que los alcanzados hasta entonces se encontraban en proceso de deterioro.

Para i83i se informó a los mexicanos que se había encargado al coronel José Rincón practicar un reconocimiento formal del estado de las obras hasta entonces logradas. ${ }^{3}$ Además de tratar de prever las inundaciones la Secretaría de Relaciones Interiores y Exteriores, en su informe anual, manifestó su preocupación por dar continuidad a las obras, pues "Lo que ganaría la salubridad es evidente, si se considera que los terrenos pantanosos, cuyas exhalaciones mefíticas infestan el aire de este valle, quedarían entonces disecados y reducidos a cultivo".4

Aunque para José Rincón la solución era que las lagunas quedaran completamente extinguidas, para la Secretaría de Relaciones esto no era lo que se pretendía en ese momento (ambas posturas continuarían teniendo adeptos a lo largo de ese siglo), pues se manifestó que las aguas que se dejasen subsistir en las lagunas y canales podían ser útiles para el tráfico interior, así como para preservar la caza y la pesca necesaria para la provisión de la capital.

Esta percepción es la que se sostenía visualmente por algunos artistas, como Conrad W ise C hapman, en su acuarela Vista de la ciudad de M éxico desde

2. Ernesto Lemoine Villicaña, El desagüe del valle de M éxico durante la época independiente, M éxico, Universidad N acional Autónoma de M éxico, 1978, p. 8o.

3. Lucas Alamán, M emoria de la Secretaría de Estado y del Despacho de Relaciones Interiores y Exteriores, M éxico, Imprenta del Águila, 183i, pp. 35-4I.

4. Lucas Alamán, M emoria de la Secretaría de Estado y del D espacho de Relaciones Interiores y Exteriores, M éxico, Imprenta del Águila, I832, p. 29. 


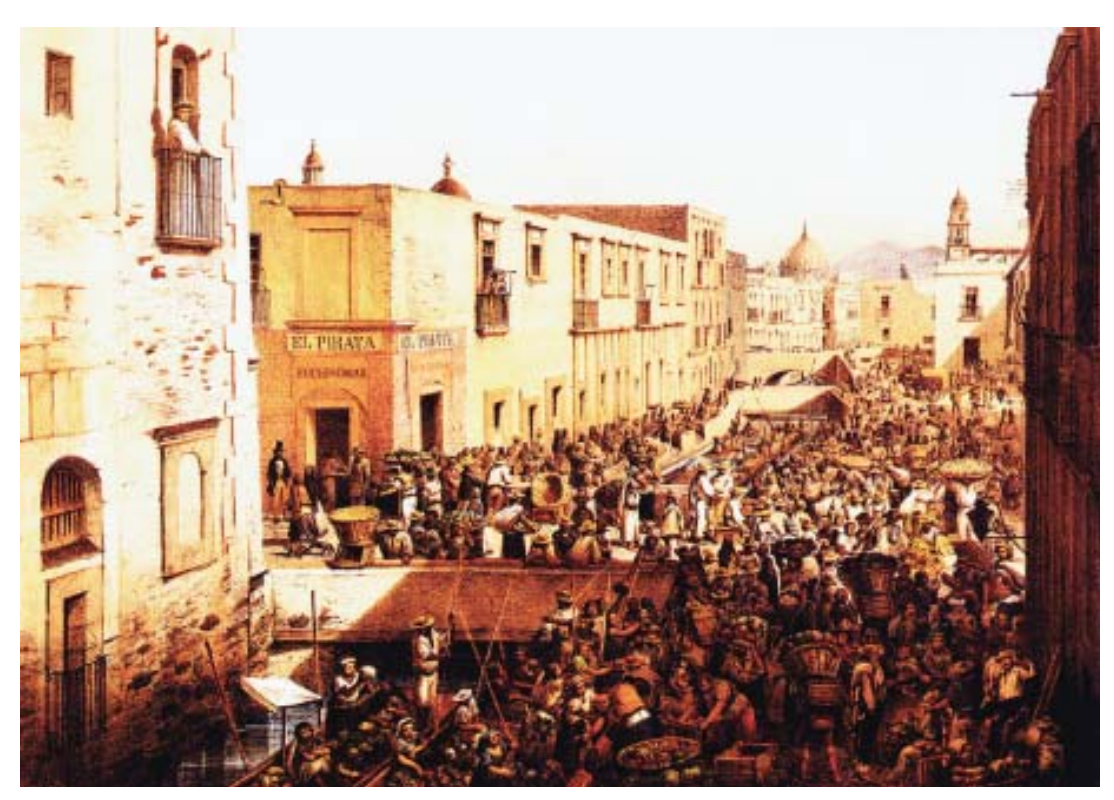

I. Casimiro C astro y J. C ampillo, La calle de Roldán y su desembarcadero, litografía en el álbum M éxico y sus al rededores, I864.

el lago de Texcoco, de i874, donde nos muestra diferentes tipos de canoas dirigiéndose a la urbe que se encuentra a lo lejos: las de pequeño calado para uno o dos pasajeros y al gún cargamento de flores y fruta impulsadas a base de una palita; la "aristocrática", de ventanas y techo curvo de madera o de hoja de lata, con los pasajeros acomodados en asientos laterales y hasta con un espacio para flores o verduras; la de toldo humilde, de estera, petate o lona, con viaje ros más modestos sentados en los bordes laterales de la embarcación.

De modo análogo, la litografía Canal de comunicación, entre los lagos de Chalco y de Texcoco, incluida en M éxico pintoresco de Rivera Cambas (I880I883), nos remite a la posibilidad de recursos desde antiguo disponibles, re presentados en esta ocasión mediante la caza de patos (aún como actividad deportiva). I gualmente, el autor agregó el desplazamiento de una ancha canoa trajinera con su voluminosa carga en costales, que en época de semana santa, en el canal de la Viga, se convertía en la embarcación propicia para el fandango acuático del "peladaje". La abundancia de pájaros es más manifiesta 
en los colores del óleo Los volcanes desde el lago de Texcoco, de Jean Baptiste Louis $\mathrm{G}$ ros (I885), donde el agua da refugio al encuentro tranquilo de aves de diferentes especies, con el poblado de $\mathrm{Chalco}$ al fondo.

Fernando Best Pontones, en i9ıI, recoge en su óleo Vista del Iztaccíhuatl desde el lago de Texcoco, una escena tradicional de pesca, con red y canasto. Todas las imágenes arriba mencionadas tienen algo en común, son vistas alejadas de la rivera de la ciudad, por ello no suministran, consciente o idílicamente, la corrupción material y social que, como diferentes escritores mencionan, se producía en las aguas inmediatas a San Lázaro.

El abasto dio al canal un movimiento constante y proporcionó escenas coloridas con los almacenes de fruta, hortalizas y otros productos. En la novela costumbrista Los bandidos de Río Frío, famosa por su amplio valor testimonial de ambientes y actitudes, M anuel Payno (I8Io-I894) representa la bondad y belleza natural de nuestro país encarnadas en el personaje de la propietaria de uno de esos establecimientos, Ilamada C ecilia.5 El viajero J. M auricio Rugendas (1802-1858), ${ }^{6}$ que visitó nuestro país entre 1831-1834, ejecutó significativamente el vigor y la prosperidad de esos comercios en el óleo Vendedora de fruta, donde el personaje central muy bien puede identificarse con la posterior exaltación de la Cecilia de Payno; ${ }^{7}$ ambos casos encarnan el arquetipo de la "china", ya muy consolidado en el siglo xix. Ella forma una unidad opulenta y prolífica, con sus jugosos y acomodados frutos, bajo el toldo de su establecimiento (que en ese momento más parece un dosel ante la aprehensiva mirada de los transeúntes).

El paisaje del canal de la Viga en los poblados ribereños de Santa Anita, I xtacalco y Xochimilco se constituía principalmente de casas de adobe en cuyas inmediaciones crecían los sembradíos de flores, legumbres y el ahuejote (como el sauce). Pero al llegar las aguas de este canal a los barrios orientales y penetrar a la ciudad por la calle de Roldán, se juntaban las aguas sucias de la ciudad con las del canal. En donde también aparecían bodegas de carbón, tocinerías, curtidurías (especialmente sobre el inmediato callejón y calles del

5. M anuel Payno, Los bandidos de Río Frío, M éxico, Porrúa, 1996, pp. 99, I02. Se publicó primero en Barcelona entre I888-I89ı. En M éxico se reeditó tardíamente hasta 1928.

6. N acido en Augsburgo, viaja entre $1822-1825$ por Brasil, a su regreso a Europa se relaciona con Alexander von Humboldt y de i83i a I846 recorre M éxico y América del Sur.

7. Claudia $O$ vando, de manera verbal, ha comentado el curioso parecido entre Cecilia y la Vendedora de fruta de Rugendas. 


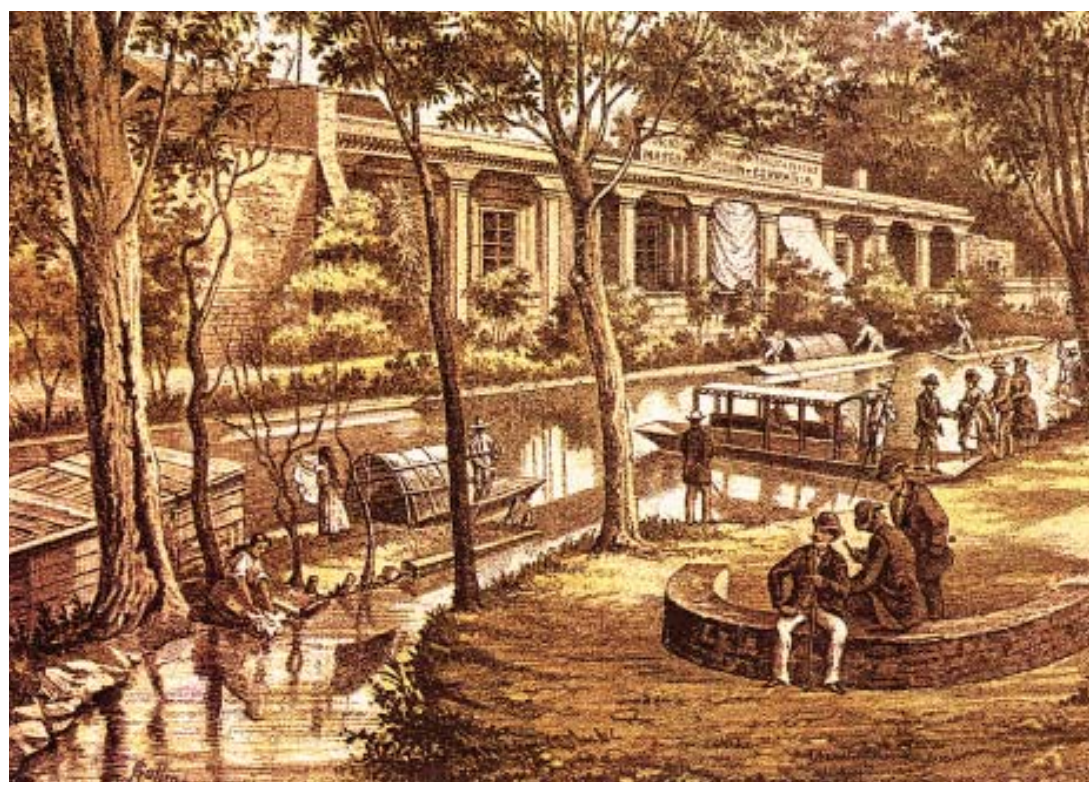

2. A. Gallice, El paseo de la Viga, detalle, cromolitografía, Álbum mexicano, i885.

Puente de Curtidores y de la D anza), ${ }^{8}$ fondas modestas, las tradicionales pulquerías, un establecimiento de estampados, ${ }^{9}$ varios molinos de aceite ${ }^{\mathrm{ro}}$ y al menos dos fábricas de jabón. ${ }^{\text {II }}$ Comercios como curtidurías y tocinerías se instalaban preferiblemente en estos barrios, donde "sus deshechos son ver-

8. Eugenio Maillefert, Directorio del comercio del imperio mexicano, M éxico, E. M aillefert, 1867, p. 272.

9. D e Luis Saabedra, en el callejón de Pacheco. AGN, Contribuciones Directas, Libro de calificación de establecimientos industriales de 1850.

Io. Entre ellos los establecidos por Pedro Padilla en la calle de Roldán; de Guillermo Ley y Santiago Tosco, ambos en el Puente del Embarcadero; de $M$ anuel $N$ ájera en Puente de Santiaguito, y de $\mathrm{M}$ anuel Huerta en el callejón de Talabartería. AGN, Contribuciones Directas, Padrón de establecimientos industriales de 1850 .

II. D eV. M ontes de 0 ca en la calle de Roldán y otra de Juan N . Zepeda en la de Curtidores y Santo Tomás. I reneo Paz y M anuel Tornel, Nueva guía de M éxico, M éxico, Imprenta de I. Paz, I882, p. 820. 
tidos en los conductos del agua que corren por aquellos suburbios, aumentando en bastante grado la aversión para habitar estos lugares". ${ }^{12}$

En los barrios coincidió la presencia de inmundicias y del inmaculado cromatismo de productos naturales que eran conducidos al interior de la ciudad, Io cual configuraba un contraste sorpresivo para los escritores, como Francisco G onzález Bocanegra. Él decía que el canal de la Viga era hermoso y cristalino en las afueras, pero que al entrar sus aguas al perímetro cercano a la calle de Roldán ya despedían un olor repugnante. Las apreciaciones de González Bocanegra fueron hechas para acompañar la litografía de Casimiro Castro y J. Campillo, La calle de Roldán y su desembarcadero (figura i), en el álbum M éxico y sus al rededores. ${ }^{13}$ Esta imagen será una excepción en los temas relacionados con el agua, aunque posteriormente será copiada y reproducida (como en la litografía M ercado en el desembarcadero de Roldán y la Alhóndiga, de Luis $\mathrm{G}$ arcés), ${ }^{\mathrm{I} 4}$ que sólo encontrará eco en otras litografías del mismo Casimiro Castro sobre mercados y fuentes públicas. Si bien es un documento costumbrista, muestra al barrio con una mirada de intromisión que se sorprende ante la escena; entre las paredes húmedas de algunos edificios, mercancía y personas se comprimen ante el espectador y crean un paisaje abigarrado y sofocante, muy acorde a la sensibilidad de la época por los miasmas, donde la corrupción de las aguas se agravaba con los efluvios del hacinamiento. Felipe Suárez, novel médico en ı888, es portador de concepciones semejantes (los miasmas, además de fomentarse por la humedad, también lo hacen por la muchedumbre en espacios reducidos), que se evidencian desde el mismo subtítulo de su trabajo: Peligrosa influencia que ejercen sobre la salud pública los cuarteles, hospitales y el canal de la Viga. ${ }^{{ }^{5}}$

I2. Gustavo Ruiz Sandoval, "¿Cuál es la influencia patogénica que tienen los lagos sobre la ciudad de M éxico?", en Gaceta M édica, núm. 5, t. VIII, M éxico, Iํ de mayo de I873, p. 75. I3. Francisco González Bocanegra, "Calle del Puente de Roldán", en M éxico y sus alrededores, colección de monumentos, trajes y paisajes, dibujados al natural y litografiados por artistas mexicanos, M éxico, Imprenta Litográfica de D ecaen, i864. Facsímil de Inversora Bursátil/Sanborns Hermanos/Seguros de M éxico, 1989, p. 26.

I4. En M anuel Rivera Cambas, M éxico pintoresco, artístico y monumental, M éxico, Imprenta de la Reforma, I880-I883, t. II, p. I94.

I5. Felipe Suárez, Algunas consi deraciones sobre higiene pública. Peligrosa influencia que ejercen sobre la salud pública los cuarteles, hospitales y el canal de la Viga, tesis inaugural para el examen general de medicina, cirugía y obstetricia, M éxico, 0 ficina Tipográfica de la Secretaría de Fomento, I888. 


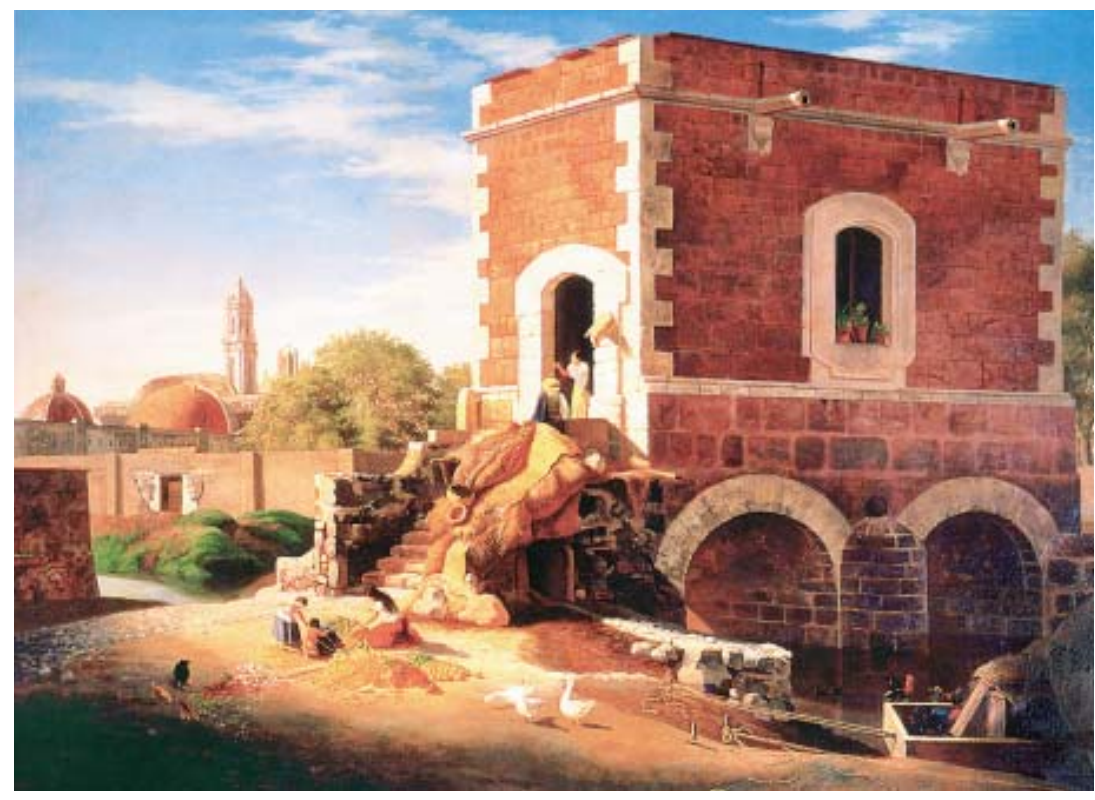

3. Luis Coto, La compuerta de San Lázaro o La garita de San Lázaro, óleo/tela, I857. Col. M useo Bello Zetina, Puebla.

Estos barrios, aún en la penúltima década del siglo decimonónico, según Rivera Cambas, estaban poblados por el sector más rezagado del populacho, vestidos con calzón blanco, pantalón hecho pedazos y enaguas zurcidas con remiendos de mil colores, de donde salían los al bañiles, tocineros, cargadores, los conductores, los curtidores, los "empedradores" de las calles y "otra porción de los que se dedican a ocupaciones para las cuales no se necesita más que seguir una rutina, sin tener que ejercitar la inteligencia", "gente de la peor clase, que entre los basureros y entre los canales que atraviesan la ciudad por aquel lado, hallan la manera de continuar los asaltos y seguir cometiendo maldades"; "esa multitud que no piensa en el día de mañana, toma el desorden por la libertad. D eallí brotan viciosos y aun bandidos de los que infestan los caminos, roban las habitaciones de la ciudad, y se abrigan entre las casuchas estrechas que forman las calles tortuosas, oscuras y sombrías de aquellos barrios". ${ }^{16}$ 
¿Pero cómo fue que esta ribera del lago deTexcoco se convirtió en una zona de degradación y en una amenaza para la salud?

\section{Formación del gran muladar de la ciudad}

Entre las causas atribuidas a las epidemias estaba la corrupción del agua estancada y la acumulación de basura, las cuales producían "emanaciones miasmáticas"; esas condiciones eran precisamente las que imperaban en el lado oriental de la urbe.

Con el crecimiento constante de la ciudad de M éxico, se generó una mayor cantidad de desechos domésticos y públicos, de los cuales se buscó desembarazarse de la manera más rápida. El lecho de los ríos, canales y acequias fueron el conducto para llevar estos residuos, en parte al Gran Canal de desagüe y en parte al lago de Texcoco.

Como se sabe, en este [lago de Texcoco] desembocan las atarjeas que con mucha lentitud conducen las aguas que han servido para los usos públicos y domésticos de la ciudad. En este vaso se vierten las materias fecales que son transportadas en vehículos especiales, y a este mismo lago van los residuos orgánicos de las curtidurías que le lleva el canal de Santo Tomás y que es el que directamente recibe las atarjeas. ${ }^{17}$

Felipe Suárez, personaje mencionado líneas arriba, señalaba que el canal de la Viga (además de ser usado para descarga de "albañales y comunes") tenía en sus orillas establecimientos industriales, de productos químicos y tejidos, que le suministraban desechos orgánicos y otros materiales contaminantes. D ecía que el canal ya no era sino: "una inmensa atarjea abierta, cuyas aguas, puras tres kilómetros antes de entrar a la ciudad, se convierten luego en una inmunda mezcla de los desperdicios de al gunas fábricas de productos químicos, de los de otra de tejidos, de muchas tenerías, ya en las calles pasa cerca del H ospital Juárez, del Rastro, del M ercado de la M erced y por último de la fábrica de gas". ${ }^{18}$ La legislación sobre limpieza urbana, además de sus inexacti- 


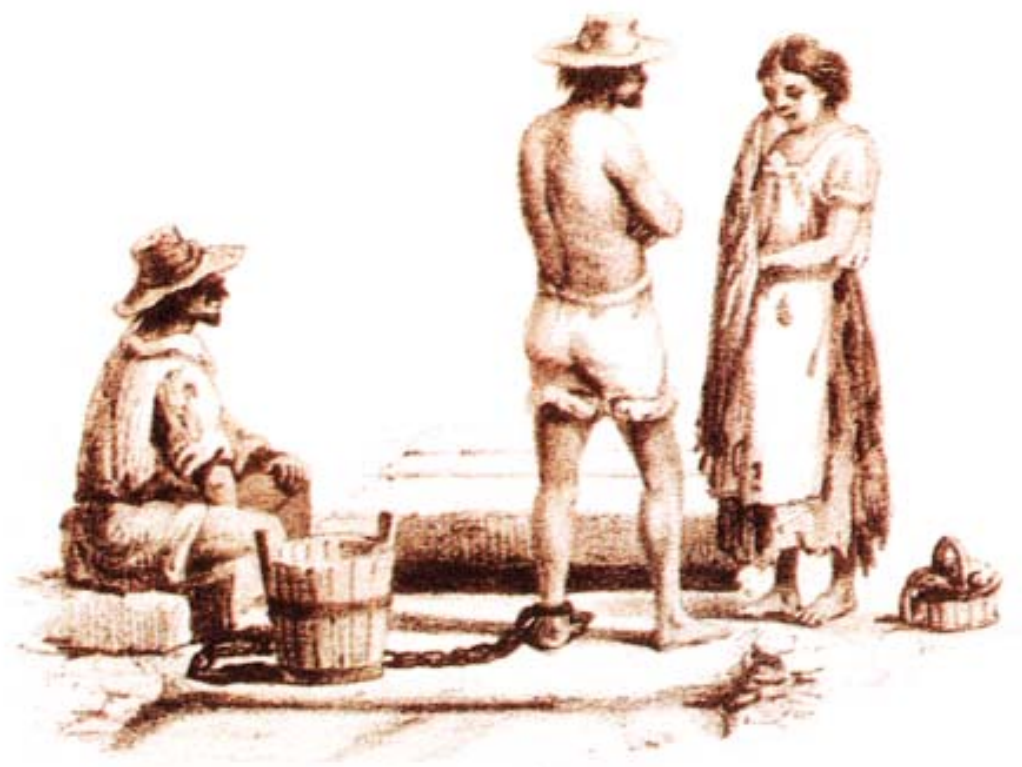

4. Casimiro C astro y J. C ampillo, detalle de la litografía Trajes mexicanos, del álbum M éxico y sus alrededores, I864.

tudes y de la corrupción administrativa, se enfrentó al siguiente dilema: ¿cómo solicitar a esos establecimientos no contaminar esas aguas si la propia ciudad y su gobierno encauzaban desde tiempo antiguo sus materiales de desecho por esos canales, como expeditos medios de drenaje?

En estas circunstancias, cerca de las ruinas de la iglesia de San Lázaro, se instaló, entre 1869 y i87i, la planta para producir gas hidrógeno bicarbonado - "extraído con preferencia, de la brea" - para el alumbrado público y particular, produciendo residuos de aceites y otras sustancias: "la separación del hidrógeno sulfurado o de otros gases, que al arder despiden olor desagradable y perjudicial, se hace por medio de baños; el agua que se emplea en el gasómetro sale por la acequia o canal de San Lázaro". ${ }^{9}$

19. Rivera Cambas, op. cit., p. 156. 
A parte de los establecimientos que ya se encontraban ensuciando el canal desde las calles de Roldán, a mediados del siglo decimonónico ya existían otros que probablemente también lo hacían sobre el propio cauce que servía de paseo en las inmediaciones de la ciudad. Entre ellos estaba la fábrica de productos químicos de $\mathrm{G}$. Keymoen (empresa que en i867 aparecía administrada por una testamentaría ${ }^{20}$ y el establecimiento para elaborar cerillos de Potnon H ermanos. ${ }^{21}$

Una cromolitografía titulada El paseo de la Viga (figura 2), firmada por A. Gallice, en el Álbum mexicano de i885 (en el cual también colaboró Casimiro Castro), constituye, además de una representación del paseo donde coexisten (aunque no conviven) las clases populares y acomodadas, un testimonio de la presencia de una de estasfábricas; en una de las riberas del famoso canal, se aprecia la fachada de una construcción con un portal, en cuyo frontispicio apenas se leen unas letras borrosas de lo que parece ser una compañía de productos químicos. $\mathrm{H}$ oy podemos indicar, gracias a un directorio comercial, ${ }^{22}$ que se trata de "Frivolin M ävers", establecimiento dedicado a producir ácidos. D e pasada y en una esquina de la escena, se representa la actividad de lavado de ropa por dos mujeres. Imagen que revela que el líquido (proveniente de la laguna de C halco y de los veneros de Xochimilco) era relativamente limpio antes de arribar a lugares como el mostrado, donde inicia la contaminación hasta constituir lo pútrido en efervescencia que mencionan varios textos de la época.

Por ello, no es extraño constatar que el canal de la Viga, cuyas aguas eran "puras tres kilómetros antes de entrar a la ciudad", al llegar a los barrios de San Lázaro se convertían en una inmunda mezcla de desperdicios. La situación se agravaba cuando los albañales y acequias, antes de descargar su contenido a esa altura del canal, se estancaban en algunos tramos, viciando "la atmósfera con su inmensa superficie de evaporación". ${ }^{23}$

20. Probablemente se trate de Juan Keymolen 0 al gún miembro de su familia que en i885 solicitó un privilegio a la Secretaría de Fomento por un "Procedimiento para la elaboración de un gas sacado de las maderas", AGN, Patentes y marcas, exp. 2I8. Eugenio M aillefert, D irectorio del comercio del imperio mexicano, M éxico, E. M aillefert, i867. Facsímil publicado por el Instituto de Investigaciones Dr. José M aría Luis M ora, 1992, p. 295.

2I. Ireneo Paz y M anuel Tornel, N ueva guía de M éxico, M éxico, Imprenta de I. Paz, I882, p. 817. 22. Ireneo Paz, op. cit., p. 8ig.

23. Felipe Suárez, op. cit., p. 20. 
Villasana realizó para una publicación periódica del M éxico del siglo xIx una litografía, ${ }^{24}$ en la cual personifica a la ciudad de M éxico como a una bella mujer, coronada, de rasgos occidentales y con una vestimenta clásica, pero desgarrada y manchada por el fango en su parte inferior, calzando unas sandalias estropeadas. La parte baja del hermoso cuerpo alude a la parte sucia que no le permite a la capital mirarse moderna; los barrios de la parte oriental, con sus construcciones húmedas, sus calles anegadas y con lodazales permanentes por la cercanía de las acequias y del lago de Texcoco, fueron un obstáculo para construcciones nuevas y de grandes dimensiones.

Como se puede apreciar, las representaciones visuales aluden muy tenue mente, casi accidentalmente, al deterioro del ambiente. Es en la litografía donde quizá se da más apertura al asunto, pero aún no como problema ambiental compartido, sino como un conflicto de los hábitos higiénicos de los otros, de los que habitaban la zona más marginada de la ciudad.

El oriente era el lado de ingreso principal a la ciudad; por ello, en un pe riódico de $\mathrm{i} 848$, se criticaba el primer impacto de su imagen descuidada. $\mathrm{Si}$ no era posible desaparecer en corto tiempo las casuchas miserables, las zanjas azolvadas, los lodazales, la basura y las emanaciones pestíferas, aconsejaba borrarlos visualmente con unas "cercas de adobe", además de formar amplios corrales para guardar el ganado (que se traía diariamente a la ordeña y las mulas que los arrieros utilizaban en las madrugadas para realizar sus viajes) y los carruajes. Así, de las cercanías de la garita, se desterrarían "al mismo tiempo las madrigueras de ladrones cercando con tapias los sitios abiertos en donde se ocultan. $Y$ con esas medidas habremos quitado uno de los focos de insalubridad y una de las peores vistas de M éxico". ${ }^{25}$ En realidad, lo anterior significaba una incapacidad o una postergación de las soluciones de fondo mediante la evasiva de "si no lo veo, no existe".

La entrada y salida de la ciudad, por la garita de San Lázaro, es un tema que no se aplicó con frecuencia en las artes (lo que sí sucedió con la garita de la Viga) y cuando se usó no se mostró con la crudeza que las descripciones literarias y científicas nos expresan; los aspectos desagradables y corruptos, de

24. D esafortunadamente lo reproduce $M$ a. del Carmen Ruiz $C$ astañeda sin indicar el título y fecha de la publicación, en La ciudad de M éxico en el siglo XIX, M éxico, D epartamento del Distrito Federal, 1974 (Colección Popular ciudad de M éxic0, 9), p. I7.

25. "M ejoras de la capital", El Eco del Comercio, i2 de julio de i848, recopilado por Ma. del Carmen Ruiz C astañeda, op. cit., p. I8. 
un paraje así, se atenuaron para dar el efecto visual académico del momento; no obstante, algunos detalles nos revelan el ambiente desaliñado. M e refiero al óleo La compuerta de San Lázaro, que Luis Coto realizó en 1857, su segundo trabajo efectuado directamente del natural (figura 3 ). En esta tela, Coto muestra una sólida y rectangular construcción, con huellas de humedad en sus paredes, y una escena costumbrista: una vendedora de frutas atenta a una joven y un niño, y algunas aves domésticas. Este pintor, discípulo de Eugenio Landesio, también plasmó en uno de los muros de la escalera, un cúmulo de petates raídos; en primera impresión, parecen secarse al sol, pero, según la descripción del Catálogo de la Exposición de la Academia de 1857, forman el toldo de una vivienda provisional. Es la única alusión que muestra un aspecto de lo que debió ser la garita en un día tranquilo.

La compuerta de San Lázaro existía ya antes de I795, pues José Antonio Alzate menciona que antiguamente era de un "ojo", pero que después se fabricó con dos arcos. ${ }^{26}$ Una lápida de mármol en el puente de mampostería de esta garita señalaba que en 1796 se dio principio a las obras del camino a Veracruz ${ }^{27}$ que allí arrancaba, quizá en ese momento se le hizo alguna restauración. Luego, en I879, sería reparado por el M inisterio de Fomento, para desaparecer como tal hacia $1903,{ }^{28}$ con la inauguración de las obras del Gran Canal de D esagüe. Además del comercio, este puente también reguló la cantidad de aguas que se retenían en la noche haciendo subir su nivel y reabrir su paso a la mañana siguiente; el sonido de las cadenas anunciaba la elevación de las compuertas de madera que permitían a los productos de las atarjeas de la ciudad ser arrastrados "con los sobrantes de las aguas potables" procedentes de los lagos de C hal co y Xochimilco. ${ }^{29} \mathrm{D}$ espués, con lentitud, la corriente era dirigida al noreste, para su desagüe.

El estado de la zona oriente era el efecto provocado por la ciudad, que sólo buscaba deshacerse de sus residuos. Al lago de Texcoco se llevaban los residuos no sólo por el líquido de las atarjeas, también se vertían las materias fecales y cadáveres de perros y gatos que eran recogidos en los domicilios, por

26. José Antonio Alzate Ramírez, Gaceta de Literatura de M éxico, vol. 3, Puebla, O ficina del H ospital de San Pedro, I831, p. 408. La edición original es de 1795.

27. Jesús Galindo y Villa, "A puntes de epigrafía mexicana", en M emorias de la Soci edad Científica Antonio Alzate, M éxico, I892-I896, t. VI, pp. I47-I48.

28. Cuando sus instalaciones son usadas por una escuela y luego como oficinas de telégrafos. Archivo del Patrimonio Inmobiliario, Secretaría de D esarrollo U rbano y Ecología, exp. 2127.

29. "Algunas observaciones higiénicas sobre la ciudad de $M$ éxico, relativamente a los lagos que la rodean", en Gaceta M édica, núm. 3, t. VIII, M éxico, Io de abril de I873, p. 48. 
las noches, en carretones o pipas especiales. ${ }^{30}$ De estos transportes una publicación periódica preguntaba: "¿Creéis que exista una gran capital en el mundo, que además de estar sentada sobre una gran cloaca tenga la fantasía de pasear desde muy tempranito en la noche los desperdicios de sus habitantes?" ${ }^{\text {i }}$ Lo que plantea esta interrogante de la época es un rasgo de la modernidad a veces olvidado: la producción y acumulación acelerada de residuos. La contradicción entre higiene y concentración de población urbana incitó el desembarazo instantáneo (a veces improvisado) de los desechos; ello fortaleció el desplazamiento del problema y no su tratamiento, hasta que el espacio destinado se saturaba produciendo una nueva coyuntura. Para entonces, ciudades europeas de Francia e Inglaterra ya enfrentaban situaciones más o menos extremas con sus desechos.

En la ciudad de M éxico, para arreglar las atarjeas de las calles, que se azolvaban por la falta de declive adecuado, se realizaban limpiezas eventuales de manera obligatoria. Esta faena debió ser frecuente, pues en una de las láminas, Trajes mexicanos, del álbum M éxico y sus al rededores (figura 4 ), C asimiro Castro incluyó, al lado de diversos tipos populares de la ciudad, a dos presidiarios en ese trabajo forzado: con un balde, y ante una atarjea abierta, dos léperos encadenados de un pie se muestran en su hedionda labor, cuando una mujer harapienta lleva a uno de ellos comida durante un intervalo de descanso.

La característica división actual de la ciudad en polos opuestos de imagen tie ne su historia. La urbeha despreciado a su parte oriental, pero es el producto de su propia forma de higiene pública y privada. Pero también los entonces linderos urbanos del norte fueron menospreciados como residencia por las clases acomodadas. La plaza de Santo D omingo, a pesar de contar con buenas construcciones, constituía una demarcación adonde el ganado lechero se concentraba.

Precisamente, entre el norte y oriente, se conformó una pequeña zona que se constituyó en signo de peligro y rechazo, pero que fue formada por los hábitos de los demás pobladores de la capital. A esa parte se le denominó Viña en el siglo xix. M anuel Payno, en Los bandidos de Río Frío, menciona que en tiempos de la conquista era un poblado al egre y floreciente pero que después fue abandonado, quizá por la falta de agua potable y lo inapropiado del terre no para el cultivo:

30. Gustavo Ruiz Sandoval, op. cit., p. 67.

3I. La Linterna del Diablo, 25 de noviembre de i875, reproducido en Ma. del Carmen Ruiz Castañeda, op. cit., p. I29. 
No sabemos ni queremos averiguar si fue un virrey o un presidente $o$ un ayuntamiento el que dispuso que se tirasen en ese lugar las basuras y los desechos más asquerosos de la ciudad [... ]

Así se fueron formando pequeñas montañas y una especie de pueblecito con sus calles y veredas, hasta el grado de que a los que no estaban habituados, trabajo les costaba salir de ese inmundo laberinto si no acertaban a orientarse por la primera torre de la ciudad que podían descubrir [... ]

Los traperos esperaban todos los días sentados en la cumbre de esas pequeñas montañas la llegada de los carretones, y sin más instrumento que un palo o un clavo grande, escarbaban hasta encontrar pedazos de fierro, platos quebrados, trapos, zapatos viejos o cualquier cosa que les pudiera producir alguna utilidad. ${ }^{32}$

Eselugar selocalizaba por el PuenteTezontlale, una de sus callesadoptó el nombre de Viña (o callejón de la Amargura), hoy forma las calles de Jaime N unó y Peralvillo, un lugar inmediato al corazón de Tepito, actual barrio de la ciudad.

Pero el mayor desdén de la época se acentuó hacia la parte oriental urbana. Ello se manifestó de diferentes maneras, como enviar las cosas indeseables a su demarcación, tal sucedió con los hospitales especializados en enfermedades contagiosas. Cuando H ernán Cortés funda el primer lazareto, lo hace en un terreno situado por el barrio de la Tlaxpana, pero al poco tiempo $\mathrm{N}$ uño de G uzmán solicitó su cambio de ubicación por el temor a "los graves perjuicios que podía traer a la ciudad de M éxico el hospital, si no se cambiaba a otra parte, pues por el lugar en que se había establecido venía el agua de Chapultepec, y de ella se aprovechaban primero los leprosos". 33

Fue aproximadamente en is72 cuando el doctor Pedro López fundó el H ospital de San Lázaro, escogiendo, como menciona Luis G onzález 0 bregón, un "punto más conveniente" al oriente de la capital. En el óleo Entrega de las llaves de la ciudad de M éxico (de i867), pintado por José C alderón (figura 5), Fausto Ramírez ha advertido en la localidad representada, por un lado y un poco alejada, la antigua iglesia y H ospital de San Lázaro (más lejos aparece un puente de piedra del canal de la Viga) y, por el otro, la puerta de la garita por donde ingresaron las tropas de la invasión francesa. ${ }^{34}$ Las características de la diversidad de

32. M anuel Payno, Los bandidos de Río Frío, p. 43.

33. Luis G onzález O bregón, M éxico viejo, M éxico, Alianza, 1992, p. I35.

34. Es la recepción a la ciudad de M éxico que da José M ariano Salas al general Forey. Fausto Ramírez, La plástica del siglo de la independencia, M éxico, Fondo Editorial de la Plástica M exicana, 1985, p. 66. 
personajes que aparecen fueron captadas con bastante certidumbre, los políticos, militares, las clases acomodadas e incluso los grupos populares peculiares de la zona, como los jóvenes con la canasta de flores y la mujer con un niño semidesnudo en la espalda. La torre y cúpula sobresal ientes de la iglesia deSan Lázaro (que actual mente ya no existen) son idénticas a las plasmadas por Luis Coto diez años antes en el ya mencionado óleo La compuerta de San Lázaro, aunque desde una perspectiva un poco más cercana y tras la barda de una huerta.

Este edificio del H ospital de San Lázaro, con su vieja iglesia y cementerio para los cadáveres de lazarinos duró muchos años, hasta que deteriorado y sin suficiente agua potable fue clausurado en i862. Para finales del siglo xix, el ex convento de San Lázaro se utilizó por Ramírez y Zepeda para elaborar jabón y por la Compañía Industrial M exicana para la producción de esencias.35 La iglesia del mismo conjunto sirvió para "una fábrica de vidrio o de ladrillo". ${ }^{6}$ Sus pacientes fueron trasladados a los de San Pablo y al Juárez, de los mismos suburbios. En este último hospital se enviaba para su atención a los criminales que padecían alguna enfermedad y a los enfermos de tifo, viruela, sarampión, escarlatina, etc. En I872 se infestó de "erisipela, y fue necesario tomar prudentes y enérgicas medidas para hacer cesar esta terrible complicación de las heridas". ${ }^{37}$ Por la parte posterior del H ospital Juárez, junto a la sala de enfermos, pasaban las aguas de una acequia con depósitos de materia orgánica vegetal y animal en descomposición que se dirigían al canal.

\section{D espoblado de oriente}

Un médico de i875 opinaba que la proximidad de las inmundicias arrojadas por la ciudad a las orillas de San Lázaro y del lago de Texcoco mantenía a esos barrios con un desagradable olor en sus calles, provocando una tendencia a emigrar. Además, la filtración de agua salobre en los terrenos impedía el cultivo y deterioraba las construcciones. ${ }^{38}$ Para el mismo galeno, las malas condiciones higiénicas no eran producto de la presencia inmediata de los

35. Adolfo Prantl y José L. Groso, La ciudad de M éxico. N ovísima guía universal de la República mexicana, M éxico, Juan Buxó y Compañía, I90I, pp. 302, 303.

36. Rivera Cambas, op. cit., p. I5o.

37. Felipe Suárez, op. cit., pp. I4-I5.

38. Gustavo Ruiz Sandoval, op. cit., p. 75. 
lagos, sino por los desechos arrojados por los establecimientos como curtidurías y la escasez de aguas potables. 39

$M$ anuel O rozco y Berra observó, en i854, que el norte (por Santiago Tlatelolco) y el este (por San Lázaro) perdían población por lo árido y triste de los terrenos y por la falta de agua potable y que, por el contrario, en el sur y el oeste (por el lado de la Ribera de San Cosme) la población crecía a gran prisa. ${ }^{\circ} \mathrm{C}$ inco años antes los capitulares del Ayuntamiento habían manifestado un criterio idéntico al juzgar que los barrios del Este y del N orte carecían de agua, mientras que los del Sur y el Poniente la tenían en abundancia, además de una mayor cantidad de arboledas. "Por tanto la población ha aumentado en los últimos rumbos [y] propende a extenderse hasta Tacubaya." $4 \mathrm{I}$

Por ello los arrabales empezaron a ser habitados por gente todavía más precaria de los que partían. Vivían casi en ruinas, en miserables casas negruzcas de adobe, en calles sin banquetas ni empedrado. M anuel Payno, al salir de la ciudad en I843, atravesando el barrio de San Lázaro en una diligencia, observa el desaseo, el peligro y lo prohibido refugiado en el lugar:

multitud de léperos, envueltos en sábanas o sucias frazadas, están bebiendo en las tabernas o jugando a la rayuela; mujeres impúdicas y sin gota de vergüenza, recogiendo las basuras de los muladares; y muchachos desnudos revolcándose en la tierra y en el lodo como unos cerdos. Este cuadro chocante en que resaltan a competencia la holgazanería y la suciedad, no da por resultado sino las bandas de ladrones que infestan los caminos y asaltan muchas veces aun las casas de la ciudad; la multitud de mujeres públicas que recorren el centro; y el hábito de la indolencia y holgazanería en la juventud, que por otra parte posee inteligencia y viveza. ${ }^{42}$

La población urbana entraba en conflicto con los barrios por las condiciones que la misma ciudad originaba; los rehusaba, los rechazaba, les negaba el agua potable y los servicios de empedrado, pero les remitía los indeseables de-

39. Ibid., pp. 74-75.

40. M anuel O rozco y Berra, H istoria de la ciudad de M éxico, desde su fundación hasta 1854 , M éxico, Secretaría de Educación Pública, I980 (SepSetentas-Diana, II2), p. 93.

4I. M anifiesto de la conducta de los capitulares que formaron el escel entísimo Ayuntamiento de esta capital. D esde 22 de julio hasta 3 de diciembre de este año, M éxico Tipografía de R. Rafael, I849, p. I5.

42. M anuel Payno, O bras completas. Crónicas de viaje, t. I, M éxico, Consejo N acional para la Cultura y las Artes, 1996, p. 49. 


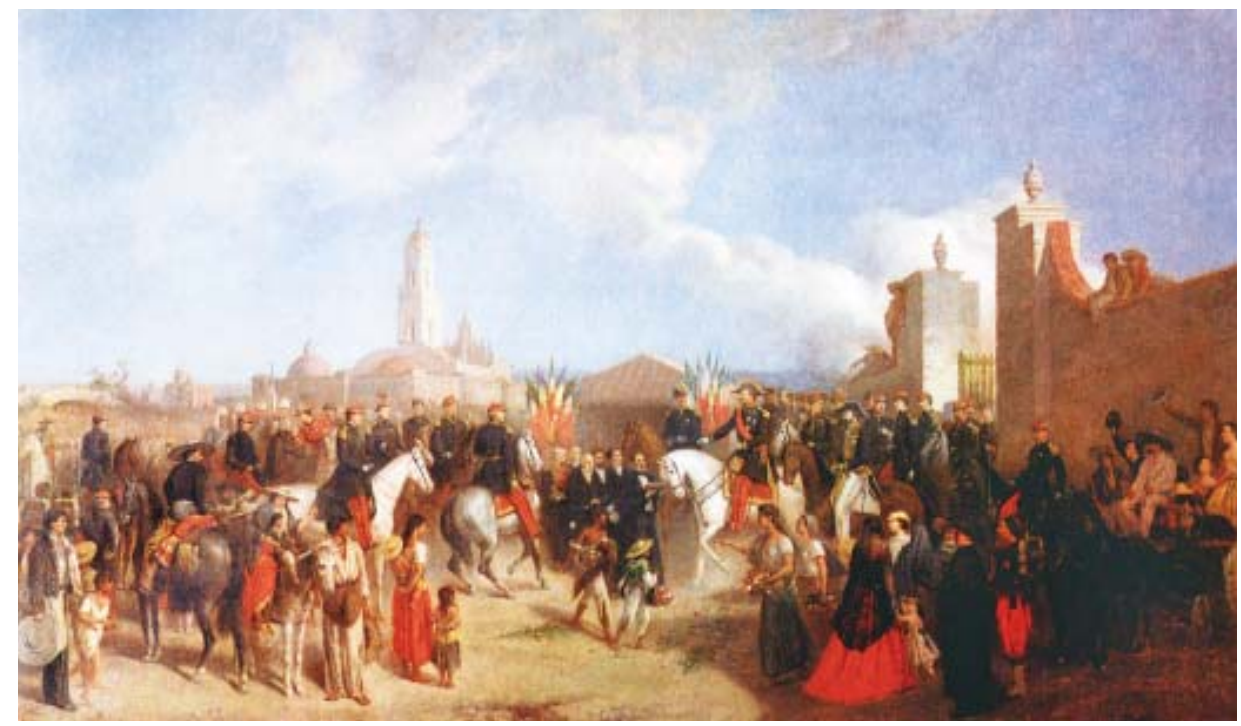

5. José M aría Calderón, Entrada del general Forey a la ciudad de M éxico el 6 de junio de 1863 , I867, detalle, óleo/tela. Col. M useo de la Ciudad de M éxico, Secretaría de Cultura del D istrito Federal.

sechos y el contagio. Para completar el cuadro, desde i882 se ideó instalar la penitenciaría de la ciudad por ese rumbo, ya que:

los vientos dominantes del $\mathrm{N}$ orte y $\mathrm{N}$ oreste no llevan sobre la ciudad los miasmas producidos por la agrupación de los presos [... ]

Además, la observación de muchos años demuestra que la población de la C apital se ensancha constantemente hacia el Noroeste, Poniente y Sur; [y] que hace largo tiempo no se construyen edificios nuevos hacia el 0 riente. 43

\section{Confrontación de lo húmedo y lo seco}

Antes de agudizarse esta polarización de la ciudad, ya desde I795, J. Antonio Alzate cuestionaba que si los pantanos eran malos como generalmente se creía,

43. José M aría Romero, La penitenciaría, M éxico, Imprenta de J. Vicente Villada, I886, p. I7. 
¿cómo habían subsistido entonces los pueblos de Ixtacalco, M exicalzingo, Xochimilco y otros, que establecidos en sus orillas "no viven mástiempo ni más sanos (que) los vecinos deTacubaya y de San Ángel, pueblos situados en terrenos muy secos?" 44

Según la antigua teoría miasmática, lo húmedo significaba corrupción y enfermedad. H umedad y vapor se relacionaban íntimamente con el aire; si el viento tocaba el agua corrupta, entonces éste propagaría en su deambular la suciedad adquirida en el líquido estancado.45 Por ello Felipe Suárez, en su tesis inaugural de medicina, de i888, era contrario a la opinión de Alzate, pues pensaba que, por estar la ciudad a un nivel más bajo, las aguas de las lagunas se filtraban a muros y pavimentos, ayudando a mantener una constante humedad del suelo, que propiciaba múltiples enfermedades, pues, "sin necesidad de ver su contenido al microscopio, se puede asegurar que en él (el canal de la Viga) existen toda esa infinidad de microorganismos animales y vegetales, que hoy figuran en la etiología de muchas enfermedades del aparato digestivo y respiratorio, así como los miasmas de al gunas fiebres". ${ }^{46}$

Por ese tipo de pensamiento sobre lo húmedo del oriente urbano, Tadeo O rtiz de Ayala, recién independizado el país, aconsejaba reorganizar la ubicación de los palacios imperiales de gobierno en "el paraje más alto, más sano" y "menos expuesto a inundaciones". 47

Si el oriente era favorable para acumular agua, el poniente y sur de la ciudad no presentaban ese problema, por lo cual fueron elegidos para paseos prolongados, realizar estancias para restablecer la salud y construir casas de veraneo (distinguidas por sus esmerados jardines).

El viajero M athieu de Fossey escribió, en I844, que en San Ángel y Tacubaya la época de lluvias fuertes no incomodaba, pues el agua resbalaba "por el declive de los cerros, en los cuales están fabricadas las aldeas, sólo humedece una ligera capa que seca el aire en breve"; Tacubaya, situada "en una colina

44. José Antonio Alzate Ramírez, op. cit., vol. 2, p. 276.

45. M arcela D ávalos, "La ciudad, el agua y los habitantes de la ciudad de M éxico. Fines del siglo xviII y principios del xix", en Regina H ernández Franyuti (comp.), La ciudad de M éxico en la primera mitad del siglo xıx. T. II, Gobierno y política/Sociedad y cultura, M éxico, Instituto de Investigaciones D r. José M aría Luis M ora, 1998, pp. 282-283.

46. Felipe Suárez, op. cit., p. 2I.

47. Simón Tadeo O rtiz de Ayala, Resumen de la estadística del imperio mexicano, I822, M éxico, Universidad N acional Autónoma de M éxico/Biblioteca N acional, 1968, pp. 30-32. 
pedregosa", y San Ángel, "fabricada en el declive de un volcán". $4^{8}$ Robert A. Wilson, otro viajero contemporáneo, se alegraba porque San Ángel tenía la ventaja de un camino casi todo seco.49

San Ángel se sitúa "sobre unas colinas en anfiteatro", en el otro rumbo de la ciudad favorecido por no tener agua pútrida y sí agua potable. En una novela de $M$ anuel Payno, se comenta que al comenzar los calores y los casos de disentería o de tifus en los barrios pobres y desaseados, los habitantes de la ciudad emigran arrebatándose el arrendamiento de las casas (ocupando aun las chozas indígenas), so por las cualidades atribuidas a este pueblo

tan sano, que muchos enfermos, aun de gravedad, con sólo el aire que respiran logran la salud en menos de dos meses. Situado a cosa de 72 varas de altura sobre el nivel de la Plaza M ayor de M éxico, el aire no está impregnado de los miasmas de letéreos producto de los desechos de una numerosa población, y el oxígeno de los pinos de la montaña y el perfume de las flores de los jardines influyen en reconstruir el organismo de una manera tan rápida que parece fabulosa. ${ }^{\text {II }}$

Para el mexicano $M$ anuel Payno, también se hacían evidentes estas ventajas en Tacubaya, pues además de disponer de buena agua para beber:

Su clima es uno de los mejores del mundo, y prueba perfectamente para la curación de algunas enfermedades y la convalecencia de casi todas. Lo seco del terreno, la muy buena ventilación, las aguas delgadas y sabrosas que posee, y el oxígeno de la multitud de árboles que ya hay plantados y crecidos, son condiciones todas necesarias para conservar la salud. .2 $^{2}$

Casimiro Castro elaboró una litografía para el famoso álbum M éxico y sus alrededores, sobre La Villa de Tacubaya. Tomada desde Chapultepec, en la cual se observa sal picando el paisaje de regias casas de campo de las clases acomoda-

48. M athieu de Fossey, Viaje a M éxico, M éxico, Consejo $\mathrm{N}$ acional para la Cultura y las Artes, 1994 (M irada viajera), pp. 155 y 156.

49. Robert A. W ilson, M exico, itsPasantsand itsPriets, I856. Citado por H ira de G ortari Rabie lay Regina H ernández Franyuti (comps.), en M emoria y encuentros. la ciudad de M éxico yel Distrito Federal (I824-1928), M éxico, D epartamento del D istrito Federal/Instituto M ora, I988, t. I, p. 67. 50. José M. G onzález, "San Ángel”, I856, en Casimiro Castro, M éxico y sus alrededores... , p. 17. 5I. Payno, Los bandidos de Río Frío, p. 456.

52. M anuel Payno, "Tacubaya", I856, en Casimiro Castro, M éxico y susalrededores... , p. 28. 
das, rodeadas de arboledas. Sólo dos o tres casitas campesinas se pierden entre los terrenos, además de una amplia magueyera y un corral que se observan como testigos de lo que fue el ambiente anterior o para completar los servicios de las nuevas construcciones invasoras.

O tra litografía del mismo álbum, con el título La Villa de Tacubaya. Tomada a ojo de pájaro sobre el camino deToluca, es ejecutada por Castro con la colaboración de J. Campillo. Es menos panorámica para poder mostrar algunos detalles del poblado; la mayoría de las casas son de uno o dos niveles, con sus portales y balcones. La mayoría de las construcciones que aparecen no son tan portentosas como algunos ejemplos existentes en el centro de la capital, pero destaca a la derecha una edificación moderna de más de tres pisos, con una monumental escalera exterior. 53

En el imaginario del siglo xix, el sur y poniente de la ciudad fueron equivalentes a salud, debido a las propiedades inherentes que les otorgaba el declive variado del terreno. Por ello las clases acomodadas se apropiaron preferentemente de estos espacios y se empeñaron en secar la cuenca de M éxico. Pero no sólo huían del polo húmedo, sino que desplazaban a ese rumbo lo negativo, lo indeseable, en ese proceso profundizaron la diferencia con sus antítesis urbanas. La polarización de la ciudad de M éxico es una tendencia de las ciudades modernas (norte-sur, oriente-poniente) que no ocurre al azar. Es producto de una tensión generada en el acomodo de los intereses opuestos de los grupos sociales contenidos, los cuales se repelen, se resisten de diversas maneras, segregándose en espacios específicos donde el bienestar y la armonía de formas llegan a ser excluyentes, conformando y reforzando a la vez inseguridad y desconcierto visual. D esde este punto de vista, las ciudades generan su propia negación. En el fondo, se desinvolucran no sólo de los demás, también lo hacen desde la perspectiva del entorno que los engloba, que los contiene.

En este panorama, la polarización de la ciudad de M éxico no podía haberse gestado de otra manera; las condiciones orográficas e hidrográficas coadyuvaron al sentido de la polarización. Pero no basta con sólo considerar esos factores naturales para comprender el proceso: la forma de percibir e interpretar los mismos elementos de la naturaleza (los atributos otorgados previamente a lo húmedo y lo seco) contribuyó a crear una estructura mental que orientó la creación de preceptos e imágenes.\$

53. Q uizá se trate de la residencia de Jamison, que M anuel Payno describe en el texto "Tacubaya", del mismo álbum en el que se presentó la litografía. 


\section{Bibliografía}

Alamán, Lucas, M emoria de la Secretaría de Estado y del Despacho de Relaciones Interiores y Exteriores, M éxico, Imprenta del Águila, I83I.

—, M emoria de la Secretaría de Estado y del Despacho de Relaciones Interiores y Exteriores, M éxico, Imprenta del Águila, I832.

"Algunas observaciones higiénicas sobre la ciudad de M éxico, relativamente a los lagos que la rodean", en Gaceta M édica, núm. 3, t. VIII, M éxico, Io de abril de I873.

Alzate Ramírez, José Antonio, Gaceta de Literatura de M éxico, vols. 2 y 3 , Puebla, $\mathrm{O}$ ficina del $\mathrm{H}$ ospital de S. Pedro, I83I.

Castro, Casimiro, M éxico y sus alrededores, colección de monumentos, trajes y paisajes, dibujados al natural y litografiados por artistas mexicanos, M éxico, edición facsimilar, Inversora Bursátil/Sanborns H ermanos/Seguros de M éxico, 1989.

Dávalos, M arcela, "La ciudad, el agua y los habitantes de la ciudad de M éxico. Fines del siglo xvir y principios del xix", en Regina Hernández Franyuti (comp.), La ciudad deM éxico en la primera mitad del siglo xIX. T. II, Gobierno y política/Sociedad y cultura, M éxico, Instituto de Investigaciones D r. José M aría Luis M ora, 1998.

Fossey, M athieu de, Viaje a M éxico, M éxico, Consejo $\mathrm{N}$ acional para la Cultura y las Artes, 1994 (M irada Viajera).

Galindo y Villa, Jesús, "Apuntes de epigrafía mexicana", en M emorias de la Sociedad Científica Antonio Alzate, M éxico, I892-I896, t. VI.

González $O$ bregón, Luis, M éxico viejo, M éxico, Alianza, 1992.

Lemoine Villicaña, Ernesto, El desagüe del valle de M éxico durante la época independiente, M éxico, Universidad Nacional Autónoma de M éxico, 1978.

$M$ aillefert, Eugenio, Directorio del comercio de imperio mexicano, M éxico, E. M aillefert, 1867, edición facsimilar, Instituto de Investigaciones Dr. José M aría Luis M ora, 1992.

$M$ anifiesto de la conducta de los capitulares que formaron el escelentísimo Ayuntamiento de esta capital. D esde 22 de julio hasta 3 de diciembre de este año, M éxico, T ipografía de R. Rafael, I849.

Musset, Alain, El agua en el valle de M éxico, M éxico, Pórtico de la ciudad de M éxico, Centro de Estudios M exicanos y Centroamericanos, 1992.

O rozco y Berra, M anuel, Historia de la ciudad de M éxico, desde su fundación hasta I854, M éxico, Secretaría de Educación Pública, 1980 (SepSetentas-Diana, II2).

Payno, M anuel, Los bandidos de Río Frío, M éxico, Porrúa, 1996.

—, O bras completas. Crónicas de viaje, M éxico, Consejo $\mathrm{N}$ acional para la Cultura y las Artes, 1996, t. I. 
DOI: http://dx.doi.org/10.22201/iie.18703062e.2003.83.2154

98

ANDRÉS RESÉNDIZ RODEA

Paz, Ireneo y M anuel Tornel, N ueva guía de M éxico, M éxico, Imprenta de I. Paz, I882. Prantl, Adolfo y José L. G roso, La ciudad de M éxico. Novísima guía universal de la Re pública mexicana, M éxico, Juan Buxó y Compañía, ı9oı.

Ramírez, Fausto, La plástica del siglo de la Independencia, M éxico, Fondo Editorial de la Plástica M exicana, 1985.

Rivera Cambas, M anuel, M éxico pintoresco, artístico y monumental, M éxico, Imprenta de la Reforma, I880-1883, t. II.

Romero, José M aría, La penitenciaría, M éxico, Imprenta de J. Vicente Villada, I886.

Ruiz C astañeda, M a. del Carmen, La ciudad de M éxico en el siglo xIx, M éxico, Departamento del Distrito Federal, 1974 (Colección Popular ciudad de M éxico, 9).

Ruiz Sandoval, Gustavo, "¿C uál es la influencia patogénica quetienen los lagos sobrela ciudad de M éxico?", en Gaceta M édica, núm. 5, t. VIII, M éxico, Io de mayo de I873.

Suárez, Felipe, Algunas consideraciones sobre higiene pública. Peligrosa influencia que ejercen sobre la salud pública los cuarteles, hospitales y el canal de la Viga, tesis inaugural para el examen general de medicina, cirugía y obstetricia, M éxico, 0 ficina Tipográfica de la Secretaría de Fomento, i888.

Tadeo O rtiz de Ayala, Simón, Resumen de la estadística del imperio mexicano, I822, M éxico, Universidad N acional Autónoma de M éxico/Biblioteca N acional, 1968.

Wilson, Robert A., M exico, its Pasants and its Priests, I856. Citado por H ira de G ortari Rabiela y Regina $\mathrm{H}$ ernández Franyuti (comps.), en M emoria y encuentros: la ciudad de M éxico y el D istrito Federal (I824-1928), M éxico, D epartamento del Distrito Federal/Instituto M ora, 1988. 